\title{
INVESTIGATION THE INFLUENCE OF SHOT PEENING TECHNIQUE ON FATIGUE CHARACTERISTICS OF ALUMINUM ALLOY 2024 - T4
}

\author{
${ }^{*}$ Haneen M. Saud ${ }^{1}$
}

Dr. Mohammed Abdulraoof Abdulrazzaq²

1) Materials Engineering Department, Mustansiriyah University, Baghdad, Iraq.

2) Assistant Prof., Materials Engineering Department, Mustansiriyah University, Baghdad, Iraq.

\begin{abstract}
This paper investigated the influence of shot peening on (AA2024-T4) at different times of peening (2, $4,6,8,16$ and $24 \mathrm{~min}$ ). It was observed the shot peening process leads to improve fatigue strength up to certain value and then fatigue life decrease. The best value of fatigue strength was (385 MPa) that obtained at 16 min. This improvement in fatigue life due to residual compressive stresses introducing on alloy's surface. Other mechanical test as hardness, roughness and tensile tests also have been investigated. The highest vales of surface hardness and roughness were (394HVN)) and (8.1 $\mu \mathrm{m})$ that obtained at $(24 \mathrm{~min})$ times of shot peening process.
\end{abstract}

Keywords: AA2024-T4; mechanical properties; shot peening technique; microhardness

\section{Introduction}

Aluminum is commonly utilized in aircraft, vehicles and wide range of applications because of high strength, light weight, good thermal and electrical conductivity, easy recycling and other beneficial properties [1]. Fatigue failure is one of the most problems in industries parts. The values of stress at which fatigue fail take place are less than the ultimate strength or beneath the yield strength of the component [2]. AA2024 T4 is generally characterized from $2 \mathrm{XXX}$ series. This alloy is characterized by having good strength, machinability, workability and other important properties [3].

Previous studies have shown that the mechanical properties of material can be promoted by shot peening technic. M. Benedetti 2009 [4] conducted the influence of shot peening on the fatigue behavior of AA7075 T651. It was found peening improve the fatigue life of the material by inserting residual compressive stresses in the surface's layers. Alalkawi H. J. M, Talal AbedAljabar and Safaa H. Alokaidi 2011) [5] carried out the influence of shot peening on mechanical properties of AA2024 $\mathrm{T}$ 351. It shown that the existence of (SP) improve mechanical properties as well fatigue life up to a limit value of SP and then the static strength decrease when ( SP) increase. Kwang Keun Oh1, Yeon Wook Kim1, and Jae Hoon Kim 2015) [6] investigated the effect of peening on the fatigue behavior of 7075T6 and Al 2024-T4 aluminum alloys. Shot peening process was carried out at various states for every materials. Results showed that the enhancement fatigue strength of AA 7075 T6 was slight while the enhancement fatigue strength of AA 2024 T4 was highest. Adnan N. Abood1 and Ali H. Saleh 2013 ) [7] investigated

*Corresponding Author: haneenmohammed52@yahoo.com 
the influence of peeing process on AA2024 T4 .Different times of peening were used to analysis the effect of time on fatigue life. The result showed that the fatigue strength improved with increase the time of peening until certain value of time. Nashwa Abdul 2016) [8] studied the effect of shot peening on fatigue characteristic of AA2024 T4. It was established the fatigue strength enhanced after penning of the surface. This enhancement due to the residual compressive stresses at the surface. Harish D.Shivalingappa, Vishnu.P and Sampath kumaran 2018) [9] Studied the influence of burnishing process on aluminum alloy 2024. Ball burnishing on surface of aluminum alloy was conducted in order to improve important properties such as surface hardness and roughness, these improvements are accomplished by inducing residual compressive stresses in the material. Results show significant enhancement in hardness and reduction in surface roughness Jinxiang Liu, Zhengxing Zuo and Huayang Zhang 2019) [10] Investigated the effect of shot peening on fretting of AA7075 T6. The results show that the relaxation of residual stress is take place near the trailing edge of contact area, and the samples with greater peening intensity subjected to greater residual stress relaxation. The residual stress near the contact region rises with the rising of loading cycles because of the fretting wear.

The purpose of the present work is to investigate the mechanical properties of AA2024 T4 alloy at different times of shot peening process.

\section{Material and Experimental}

\subsection{Material}

Material utilized in this work is AA 2024 T4, The chemical analysis of aluminum alloy is carried out by (optical emission spectrometer). The chemical composition is given in "Table 1".The as-received alloy was stress relived at $300{ }^{\circ} \mathrm{C}$ for 1 hour. This test accomplished at $28^{\circ} \mathrm{C}$ and moisture $29 \%$.

\begin{tabular}{lll}
\multicolumn{3}{l}{ Table 1 Chemical analysis of (AA2024 T 4) } \\
\hline Element & $\begin{array}{c}2024 \mathrm{~T} 4 \\
\text { experimental }\end{array}$ & $\begin{array}{c}\text { 2024 T4 } \\
\text { ASTM } \\
\text { B209[1] }\end{array}$ \\
$\mathrm{Si} \%$ & 0.251 & 0.5 \\
$\mathrm{Fe} \%$ & 0.375 & 0.5 \\
$\mathrm{Cu}$ & 4.07 & $3.8-4.9$ \\
$\%$ & & \\
$\mathrm{Mn}$ & 0.473 & $0.3-0.9$ \\
$\%$ & & \\
$\mathrm{Mg}$ & 0.421 & $1.2-1.8$ \\
$\%$ & & \\
$\mathrm{Cr}$ & 0.052 & 0.1 \\
$\%$ & & \\
$\mathrm{Zn}$ & 0.120 & 0.25 \\
$\%$ & & \\
$\mathrm{Al} \%$ & Bal & Bal \\
\hline
\end{tabular}

\subsection{Properties of tensile and fatigue samples}

The samples for tensile and fatigue tests were manufactured according to ASTM A (370) [12] and DIN (50113) [13] respectively as shown in the "Fig. 1" And "Fig. 2". Samples of fatigue and tensile were fabricated by (Harrison 600 series engine lathe, Model 350).

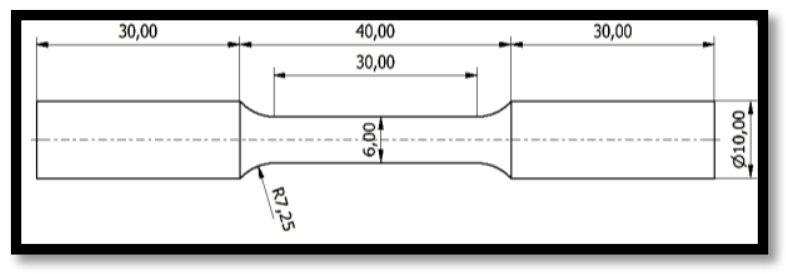

Figure 1.Sample of the tensile test

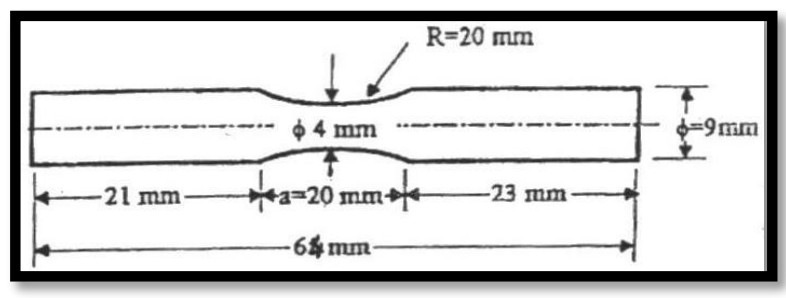

Figure 2. Sample of the fatigue test 


\subsection{Tensile test}

This test were accomplished by using a device namely (Tinius Olsen H100KU Model), as shown in "Fig. 3".The device is done with maximum capacity $(150 \mathrm{KN})$ and speed (1) $\mathrm{mm}$ $/ \mathrm{min}$. This test was carried out for the samples of aluminum alloy (2024 T4) after finishing stress relieve process of all samples. To get accurate values of tensile test the average of three reading of tensile test are obtained. The results of mechanical properties of tensile test is given in "Table 2".

Table 2. Mechanical properties of AA2024 T4

\begin{tabular}{llll}
\hline Element & $\begin{array}{l}\text { Tensile } \\
\text { Strength } \\
(\mathrm{M} \mathrm{Pa})\end{array}$ & $\begin{array}{l}\text { Yield } \\
\text { Strength } \\
(\mathrm{M} \mathrm{Pa})\end{array}$ & $\begin{array}{l}\text { Elongation } \\
(\%)\end{array}$ \\
2024-T4 & 469 & 325 & 20 \\
& & 306 & 18 \\
$\begin{array}{l}\text { 2024-T4 } \\
\text { Experimental }\end{array}$ & 416 & 306 & \\
\hline
\end{tabular}

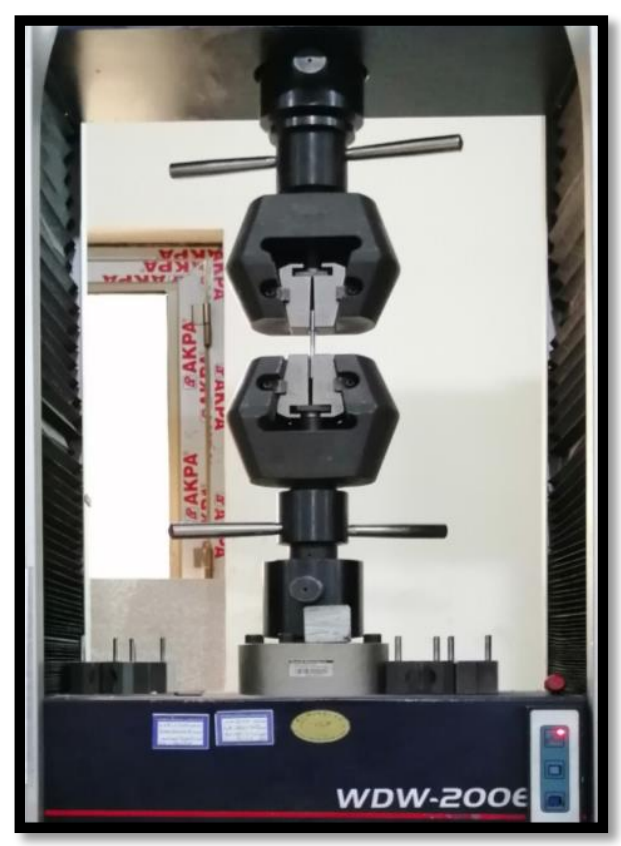

Figure 3. Device of Tensile test

\subsection{Shot peening properties}

The shot peening process is performed by airblast machine (Shot tumblast Control Panel). A ball shot of steel with the hardness of (55) HRC (hardness Rockwell C) with diameter (1mm). "Fig.4". Illustrates the shot peening device. Shot Peening is done for six exposure time conditions (2, 4, 6,8,16 and 24 minutes), "Fig.5" explained the samples after shot peening. Data of peening has been obtained by using ten specimens for every condition

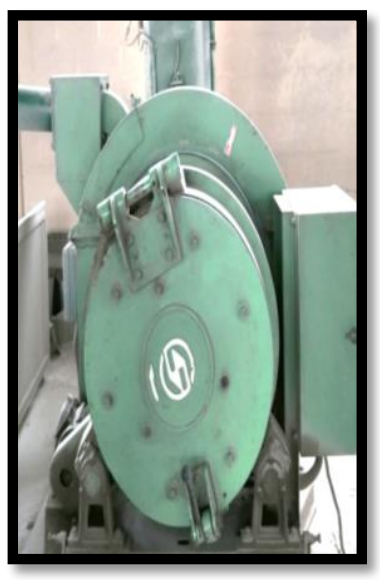

(a)

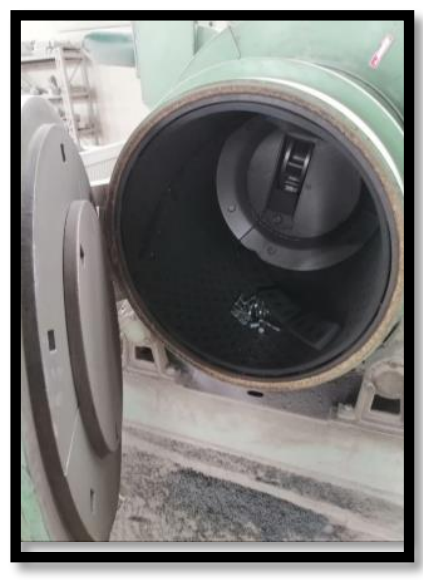

(b)
Figure 4. Shot Peening Device (a) from outside (b) from inside with the samples and shots

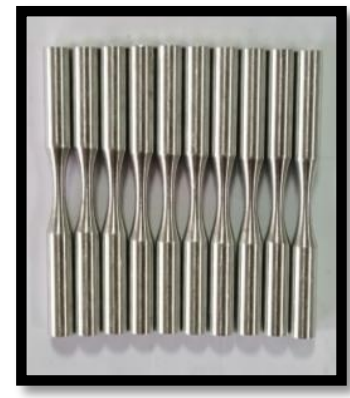

(a)

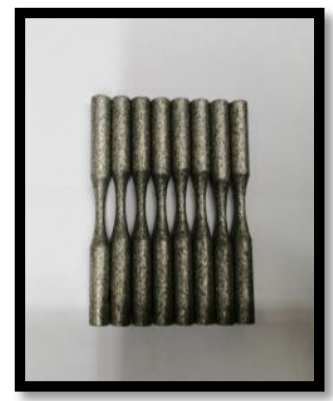

(b)
Figure 5. Samples of fatigue (a) before shot beening (b) after shot peening 


\subsection{Fatigue test}

Fatigue tests were conducted out by machine type of (HSM20) is the rotating bending type as shown in "Fig.6". Fatigue test are performed for two groups consist of as received and shot peening samples. In shot peening process different values of time were used to analysis the effect of time on fatigue resistance. Data has been gained by using ten specimens for every condition. These tests are performed at stress ratio $(\mathrm{R}=-1)$ and different value of applied stresses depending on the tensile test.

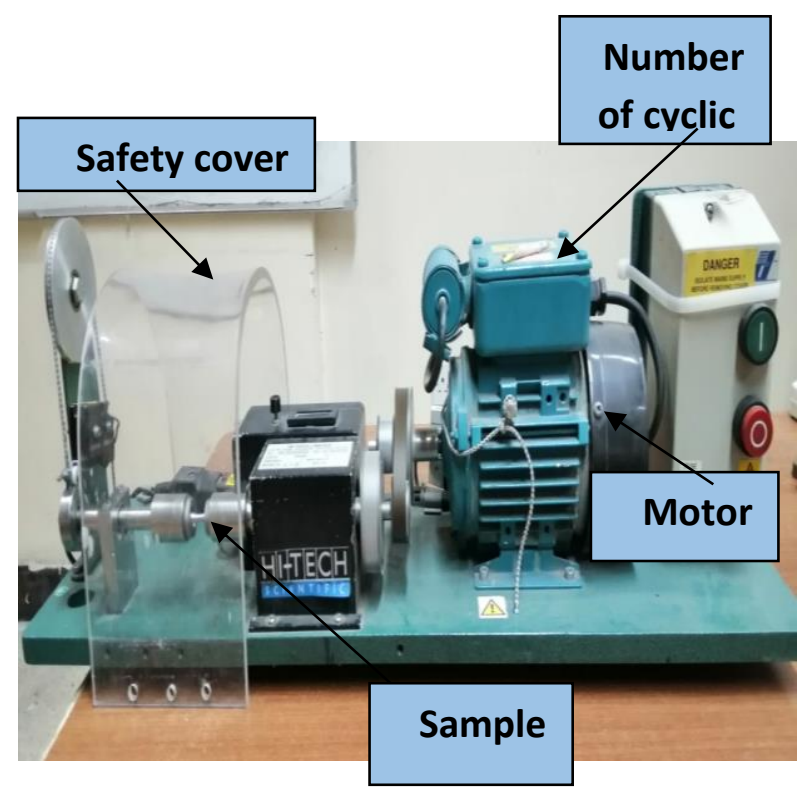

Figure 6. Fatigue testing machine HSM20 (rotary bending)

\subsection{Micro hardness test}

Micro hardness test is carried out by using (INNOVA test) as shown in the "Fig. 7 '.Vickers scale is used in this test with load of $(3 \mathrm{~N})$ and time of holding $(10 \mathrm{sec})$. The depth of indentations were produced starting $(0.25 \mathrm{~mm})$ from end at a spacing of $(0.25) \mathrm{mm}$ to interval of $3 \mathrm{~mm}$ across medium. To get accurate values of microhardness test the average of ten readings are obtained for each condition. "Table 3"how the values of hardness test for samples of (AA 2024T 4) .

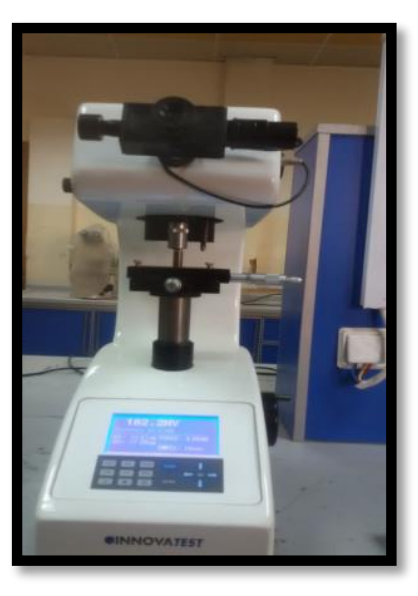

(a)

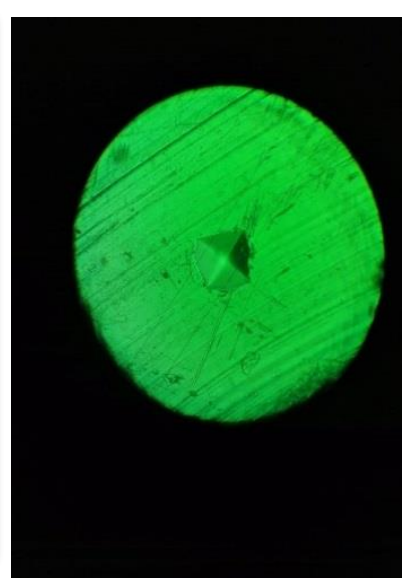

(b)
Figure 7. Microhardness test (a) (INNOVA test) (b) The depth of indentation

Table 3. The values of hardness test for samples of (AA 2024T 4)

$\begin{array}{lc}\text { Time of shot peening } & \begin{array}{c}\text { microhardness average } \\ \text { (HVN) }\end{array} \\ \text { Shot peening for } 2 \mathrm{~min} & 153.92 \\ \text { Shot peening for } 4 \mathrm{~min} & 167.51 \\ \text { Shot peening for } 6 \mathrm{~min} & 181.69 \\ \text { Shot peening for } 8 \mathrm{~min} & 198.19 \\ \text { Shot peening for } 16 \mathrm{~min} & 283.79 \\ \text { Shot peening for } 24 \mathrm{~min} & 394.5\end{array}$

\subsection{Surface roughness}

The surface roughness test was accomplished by device namely (Pocket surf Mahr) as shown in the "Fig. 8". To obtained accurate values of surface roughness the average of ten readings are obtained for each condition of as received 
and shot peening samples. "Table 4"show the values of roughness test.

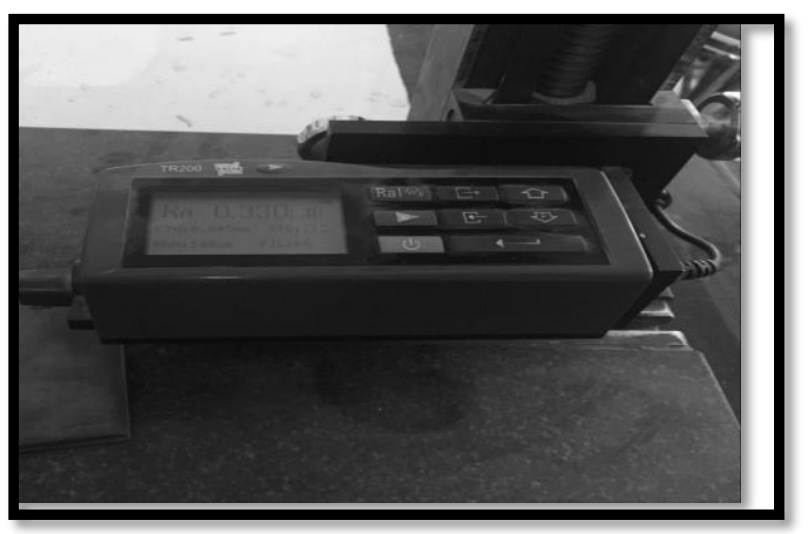

Figure 8. Device of Surface roughness test

Table 4. The values of surface roughness for samples of (AA 2024T 4)
Time of shot peening

As received alloy

Shot peening for 2

Min

Shot peening for 4 $\min$

Shot peening for 6 $\min$

Shot peening for 8 $\min$

Shot peening for 16 $\min$

Shot peening for 24 $\min$
Surface roughness average $(\mu \mathrm{m})$

0.8

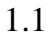

3

8.4

\section{Results}

\subsection{Fatigue test}

It was observed the shot peening process leads to improve fatigue strength, with increase time of shot peening the tensile strength and yield strength increased slightly until 16 minutes after this value the fatigue strength was decrease. "Fig. 9" illustrated for as received and shot peening samples. This enhancement in fatigue life because of residual compressive stresses that introducing on the component's surface. This residual stresses leads to deny initiation and propagation of cracks [14]. Reason for decrease in fatigue strength after $16 \mathrm{~min}$, the shot peening will have double effect, residual stresses and strain hardening as a result of increase the density of dislocation. This will lead to increase the yield strength at the surface of the component.

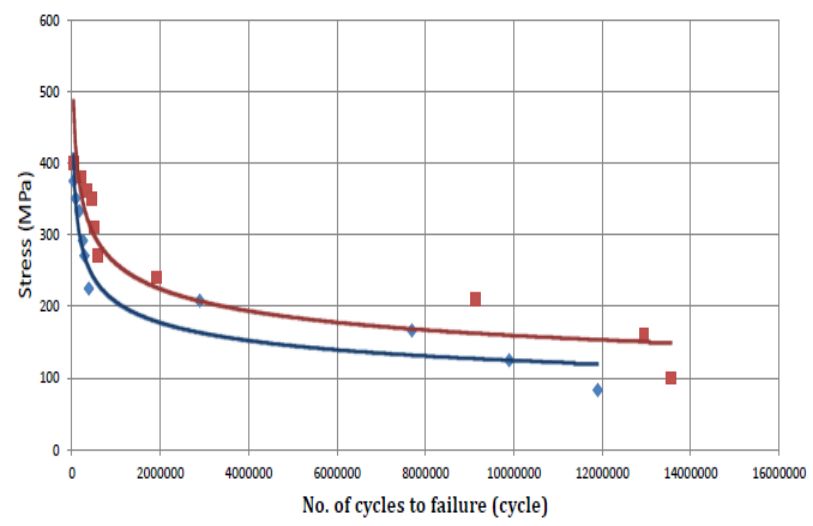

- received aluminium alloy (2024 T4)

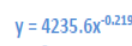

$y=4900.9 x^{-0.212}$ -16 shot peening aluminium alloy (2024 T4)
$R^{2}=0.8207$ $R^{2}=0.8695$

Figure 9. S-N curve for peened and unpeened samples

\subsection{Hardness and roughness tests}

The results show that surface hardness improved for the samples generally treated with shot peening. This improvement in surface hardness of sample due to residual compressive stresses, which increased the density of dislocations and led to increase the surface hardness of alloy. The highest value of surface hardness was (394.5 HVN) for samples treated with (24 minutes) time of peening as explained in the "Fig. 10". 


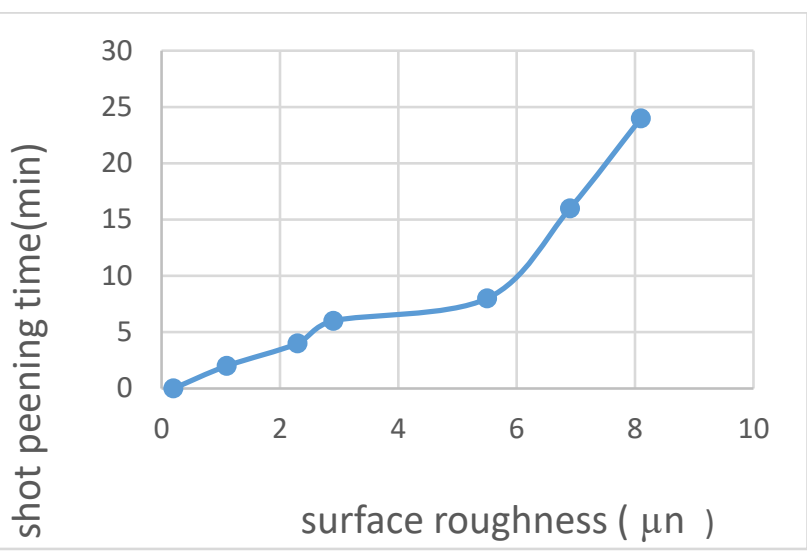

Figure 10. Effect time of shot peening on surface hardness

It was found the effect of shot peening on specimens is very strong and have a significant increase in surface roughness with increasing time. This increasing in surface roughness because of valleys and peaks that produce on metal's surface with increasing the temperature of the surface .The temperature of the surface increase when time of shots incident increase and this will be lead to losses fineness of the surface. The highest value of surface roughness was $(8.4 \mu \mathrm{m})$ for samples treated with (24 minutes) time of peening as explained in the "Fig. 11".

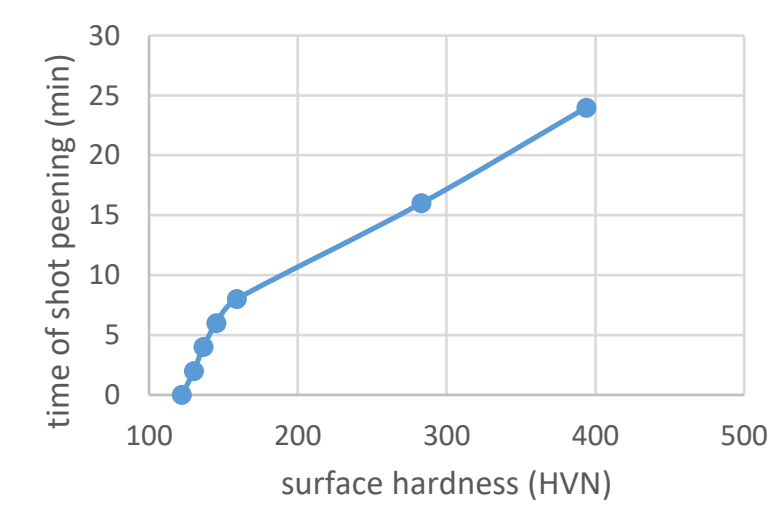

Figure 11. Effect time of shot peening on surface hardness

\section{Conclusions}

1- The fatigue strength of (AA2024-T4) is enhanced by shot peening process. This enhancement because of compressive residual stresses at the introduce on the surface

2- The favourite case of peening process at which fatigue strength improved that obtained at 16 $\min$.

3- Surface hardness improved for the samples treated with shot peening. This improvement in surface hardness because of compressive residual stresses induced in the surface.

4- Surface roughness increase with rising the time of peening, this due to compressive residual stresses and strain hardening.

\section{Acknowledgements}

The authors would like to thank Mustansiriyah university (www.uomustaanansiriyah.edu.iq) Baghdad - Iraq, for their support in present work.

\section{Conflict of interest}

The publication of this article causes no conflict of interest.

\section{References}

1. Ö. Karakasi and J. Szusta. (2015). "Monotonic and low cycle fatigue behavior of 2024-T3 aluminum alloy between room temperature and $300{ }^{\circ} \mathrm{C}$ for designing VAWT components ". Fatigue and fracture of engineering materials and structures, vol.39, p. 95-109.

2. A. Qandil1 and Adnan I. O. Zaid. (2016). "Effect of shot peening and grain refinement on the fatigue life and strength of commercially pure $\mathrm{Al}$ and two of its alloys: Al-2024-T3 and Al-7075-T6". Materials Science and Engineering. vol. 146 . 
3. Yashpal, C.S. Jawalkar and Suman Kant. (2015). "A review on use of aluminum alloys in aircraft Components". Journal on Material Science, Vol. 3.

4. M.Tajally, Z.Huda and H.H. Masjuki. (2009). "The effect of cold rolling on bending and tensile behavior of 7075 aluminum alloys". Journal of Applied Sciences, Vol 9, pp. 38883893 .

5. Alalkawi H. J. M, Talal Abed-Aljabar and Safaa H. Alokaidi. (2011). "Analysis the Effects of Shot Peening Upon the Mechanical and Fatigue Properties of 2024-T351 AlAlloy". Journal of engineering and technology, vol 30 .

6. Kwang Keun Oh1, Yeon Wook Kim1, and Jae Hoon. (2015). "High cycle Fatigue characteristics of aluminum alloy by shot peening". Journal of Advanced Materials Research, Vol. 1110, pp. 142-147 .

7. Adnan N. Abood1, Ali H. Saleh2, Raid K. Salem1, Ghaith A. Kadhim1 and Zainab W. Abdullah. (2013). "Strain Life of Shot Peening AA 2024-T4". Journal of Materials Science Research, Vol. 2.

8. Hussain J. M. Alalkawi Rawaa, Hamid AlKalali and Shatha M.R. Abdul Jabbar. (2016)." Investigation of fatigue behavior using surface shot peened Technique for 2024 - T4 Al-alloy". The Iraqi Journal for Mechanical and Material Engineering, Vol.16.

9. Harish, D.Shivalingappa, Vishnu.P and Sampath kumaran. (2018). "Impact of Ball burnishing process parameters on surface Integrity of an Aluminum 2024 Alloy". Materials Science and Engineering, vol.376.

10. Xin Liu, Jinxiang Liu, Zhengxing Zuo and Huayang Zhang. (2019). "Numerical study on residual stress redistribution of shot-peened aluminum 7075-T6 under fretting loading" .International Journal of Mechanical Sciences vol.160, p.p156-164.
11. Annual Book of ASTM Standards. (2009). "Standard Specification for Aluminum and Aluminum-Alloy Sheet and Plate". American Society for Testing and Material, Vol. 02.02, p 298 .

12. J. M. Hussain AL-alkawi, S. H. Shakir and F. A. Salah. (2013). "Experimental Study of the Effect of Shot Peening on Elevated Temperature Fatigue Behavior of 7075-T651 Al. alloy". Eng. and Tech. Journal, Vol.31, PP. 416-433.

13. H. J. Hasan. (2013). "Deflection and Noises Measurement Using Sensor Device under Dynamic Loading". MSc. Thesis, University of Technology Electromechanical Engineering Department.

14. Arken J. Lu, J. Flavenot. (1990) . "Effect of Glass Beads Nature on the behavior of shot peened". Fourth edition, internal conference ob shot peening (ICSP-4), Japan. 